\title{
Editorial
}

\section{Softening up the marketplace for skills}

\author{
Journal of Direct, Data and Digital Marketing Practice (2014) 16, 69-70. doi:10.1057/dddmp.2014.61
}

As you might expect from the official publication of a training institution, the IDM Journal pays close attention to the ongoing demands of the marketplace in terms of the skills that employers are looking for and the demand from practitioners for new areas of knowledge. This is reflected in the opinion pieces we carry that focus on how the academic and commercial worlds are trying to become better aligned (see Merlin Stone's piece in Issue 16.1 as an example).

Yet there are also some recruitment and training issues that are both more pressing and also far harder to deal with. At the top of the agenda currently I would place two key themes: the under-representation of women at a senior level in certain roles, specifically data and analytics, and the pressure on analysts to transform from back office specialists into front office performers.

To take the first of these head on, every reader of the IDM Journal will undoubtedly have had a similar experience to the one I had recently of attending a software vendor's conference where 90 per cent of the delegates and 100 per cent of the presenters were male. This is clearly not a deliberate policy - speakers are chosen based on the quality of what they have to say, rather than gender, while conference places are sold on a first-come, first-served basis with the organizers effectively blind to who is coming.

So the profile of both those onstage and those watching them clearly represents the broader demographic of this sector. In the instance quoted above, the vendor specializes in analytics and data visualizations - the sort of cutting-edge areas that have an urgent need for talented practitioners to help sustain current growth. If the companies making use of these techniques are sending mostly men to such events, this can only reflect a male-dominated profile among their employees.

Why should this be the case? It has long been recognized that mathematics and scientific subjects have struggled to attract female students, especially in higher education. Social conditions and acculturation seem to play a larger part in explaining this than any fundamental difference between the mental abilities of either sex.

With all young people now required to achieve a C grade at maths GCSE or continue to study the subject, we should begin to see a closing of the gap between the subjects that boys and girls choose and therefore more female mathematicians. But it will be at least a decade before this has an impact on the profile of graduates.

Is positive discrimination the answer? Such policies seldom work and are impossible to enforce in the commercial world. Many women also object to the idea of being chosen because of their gender, rather than based purely on ability. Instead, a better idea seems to be promoting success stories where they can be found and putting more pressure on businesses to address this gender divide. If you have any examples or thoughts you'd like to share, there is already a Twitter hashtag devoted to the subject: \#datawomen.

When it comes to the second challenge — turning analysts into communicators - there are just as many difficulties. It's obvious that the core tasks (data manipulation, analytics and modelling) are critical and need to be done right. That is why recruitment briefs for insight and analytics roles concentrate on a (almost impossible to fill) range of abilities, covering the mathematical, statistical, data and programming. But none of that effort has any value if its output cannot be delivered to the business in a way it can understand, accept and adopt.

Typically, presentation and communication skills do not form part of the academic curriculum, beyond some schooling in PowerPoint or some casual lecturing. Given the pace at which businesses 
and marketers need to get actionable insights, there is not time to run through the way a model has been built, what was done to normalize the data or how the analyst found the perfect fit between the two.

Marketing is a world of elevator pitches, 12-word summaries and failing faster. Academics seldom have exposure to that pace of life.

Universities are also not necessarily the right places for these kind of soft skills to be learned.

Equally, most courses that do offer this type of training are not sector or skills specific. Will a young, introverted analyst want to attend a storytelling course among a lot of wannabe screenwriters, for example?

Instead, this looks like an ideal opportunity for in-company training and career development programmes, specifically architected around the exact skills base and requirements of the insight and analytical community. Any company (end-user, agency or vendor) that supports its teams in that way would likely see real loyalty develop and enhance its status as a good place to work. Which makes it a win-win on both sides.

Social engineering may look beyond the remit of marketing (and this Journal). Yet unless something happens that encourages a greater flow of candidates - from women taking up maths and sciences through to scientists feeling confident they can thrive in a commercial environment - there is a real risk that the current data and analytics revolution will peter out in the face of a lack of human resources.

David Reed FIDM 